\title{
The perceptions of women on child birthing in a public-health facility in a peri-urban area in Kavango east region, Namibia
}

\author{
Bartholomeus M Muntenda ${ }^{1}$, Vistolina Nuuyoma*2, Ruth Stern ${ }^{1}$ \\ ${ }^{1}$ School of Public Health, University of the Western Cape, South Africa \\ ${ }^{2}$ Faculty of Health Sciences, University of Namibia, Namibia
}

Received: May 17, 2017

DOI: $10.5430 /$ ijh.v3n2p37
Accepted: July 6, 2017

URL: https://doi.org/10.5430/ijh.v3n2p37
Online Published: July 25, 2017

\begin{abstract}
Purpose: The study explored the perceptions of women on child birthing in a public-health facility in a peri-urban area of the Kavango east region.

Methods: A qualitative case study was conducted with women residing in Kehemu settlement, who have given birth either using a public-health facility or outside a public facility with the assistance of traditional birth attendants. Data were collected via three focus group discussions with 21 women $(n=21)$ who were purposively selected. Discussions were conducted in a local language and all were audio recorded with the participants' permission. Data were transcribed and translated into English for analysis. The process of data reduction was used to analyse the study data.

Results: Women were found to prefer child birthing at a public hospital because they considered nurses and midwives to be knowledgeable, caring and skilled people with regard to managing a woman in labour. However, although some women prefer to deliver at a public hospital, circumstances such as lack of transport - especially at night-time - prevent them from reaching the hospital. Moreover, some women indicated that nurses' attitudes, the ill timing of labour and the wrong advice were hindrances to public hospital child birthing. Women stated more nurses, more supplies of the items used in child birthing, the provision of pain relief during labour, and a change in nurses' attitudes as being some of the improvements which would make public hospital maternity wards more user-friendly.

Conclusions: The women perceived child birthing at the public-health facility as being generally good, affordable and acceptable. However, there is a need for more interventions to make the public-health facility more user-friendly and accessible to all.
\end{abstract}

Key Words: Public obstetric care, Pregnant women, Child birth, Antenatal care, Kavango east region, Kehemu settlement

\section{INTRODUCTION}

It is estimated that 830 women died globally due to pregnancy and childbirth complications every day in 2015. Of the estimated number of deaths per day, 550 occurred in subSaharan Africa. ${ }^{[1]}$ These deaths could have been prevented but occurred in low-resource settings where preventable measures are limited.

Namibia is part of the sub-Saharan region and has recorded an ascending trend in the maternal and neonatal mortality rate - from 225 to 449 per 100,000 women and from 38 to

\footnotetext{
* Correspondence: Vistolina Nuuyoma; Email: vistolina.nuuyoma@ gmail.com; Address: Faculty of Health Sciences, University of Namibia, P.O. Box 602, Keetmanshoop, Namibia.
} 
46 per 1,000 live births, during the period 2000 to 2006, respectively. ${ }^{[2]}$ However, the 2013 Namibia Demographic and Health Survey (NDHS) reported a maternal mortality rate of 385 deaths per 100,000 women and a neonatal mortality rate of 20 deaths per 1,000 live births, ${ }^{[3]}$ which represents a reduction in mortality rates.

Kavango Region is located in north-eastern Namibia and is one among the top seven regions with a high maternal and neonatal mortality rate in the country. A neonatal rate of 27 deaths per 1,000 live births was reported in Kavango Region, and, in addition, the maternal mortality rate is also above the national estimate. ${ }^{[3]}$ In Namibia, access to emergency obstetric care is unevenly distributed. This is because health care facilities in some regions are not adequately equipped with life-saving equipment and midwives still do not possess the necessary skill to provide emergency obstetric and neonatal care services, ${ }^{[3]}$ thus contributing to the high mortality rates in some regions, including Kavango east. In addition, the 2013 NDHS reported that $46.6 \%$ of women in Kavango Region deliver their babies at home with assistance of traditional birth attendants (TBAs) or family members who are not trained as midwives. ${ }^{[3]}$ This makes it the region in Namibia where most deliveries occur at home. This is despite many women attending ante-natal services at public-health facilities. It is observed that women who attend ante-natal care (ANC) at health-care facilities do not use services at the hospital when it is time for delivery. It is also observed that women who delivered their babies with the assistance of TBAs or family members are mostly from the lowest wealth quintile. ${ }^{[3]}$

The use of maternity health services is influenced by both access to and the acceptability of the services. Access to services is influenced by several factors, including the distance that women have to travel or walk to the health facilities and the system of user fees. ${ }^{[4]}$ Other factors include the acceptability of the services, the attitudes and skills of the health-care providers and the influence of negative exposure relating to health-care services in the media. Acceptability is also influenced by the availability of resources at the health facilities, with aspects noted including privacy, appropriate equipment, reliability in timing, and the availability of skilled personnel in the provision of services. ${ }^{[5]}$ Fear of the unknown and lack of confidentiality were further concerns, particularly among women with a low level of education. ${ }^{[6]}$

Maimbolwa et al. ${ }^{[7]}$ suggest that women who have negative perceptions of public maternity care services will be more likely to make use of alternative choices because of what they perceive to be the benefits of alternative services. Alternative choices are mainly the use of indigenous skilled per- sons who provide health-care. ${ }^{[7]}$ TBAs are indigenous people who assist pregnant women during pregnancy and child birth, but without a formal professional training and without registration or a licence to practise. ${ }^{[8]}$ In Namibia, TBAs are expected to be registered with their boards. However, some operate without being registered. Most TBAs conduct their services in the clients' home environment. In general, the safety of home birth is context dependent; however, in Namibia, the choice of using TBA services for childbirth is a risk to pregnant women and their babies. This is because individuals who assist women giving birth are not trained and childbirths are conducted under unhygienic conditions. Therefore all pregnant women are encouraged to deliver in health facilities where they are assisted by health-care professionals. There are reported cases of mothers and babies who have died after home childbirth in Namibia. However, there is no evidence of any study conducted on the outcomes of homebirths and its relations to maternal and neonatal mortality. In a study conducted in Indonesia, a home delivery is one of the factors which are concluded to be significantly associated with a higher risk of neonatal death. ${ }^{[9]}$

Most pregnant women in the Kavango east peri-urban areas attend ANC services, but most do not use public-health facilities for delivery. The health records from a clinic and maternity ward revealed that, although $80 \%$ of pregnant women attended ANC three times or more, which is in line with the national guidelines, ${ }^{[10]}$ over $40 \%$ of women who attend public ANC clinics do not deliver in a public-health facility. ${ }^{[10]}$ There is therefore a need to conduct a systematic investigation to answer the following question: Why do most women from Kavango east region not use public-health facilities for child birthing?

\subsection{Aim}

We explored the perceptions of women on child birthing in public-health facilities in a peri-urban area in Kavango east, Namibia.

\subsection{Objectives}

Our objectives were to:

(1) Explore the perception of women on the acceptability of child birthing services provided in the public-health facilities concerned;

(2) Describe the experiences of women who delivered in the public hospital concerned;

(3) Explore the women's opinion on how the childbirth services could be improved. 


\subsection{Setting}

The study was conducted in a district located in the north-east of Namibia. Twenty-four per cent (24\%) of the population there are women of child-bearing age (15-49 years). ${ }^{[11]}$ There is only one town in the district and it serves as a regional centre for the region. Forty per cent (40\%) of the town's population reside in Kehemu - one of the three peri-urban settlements of the town.

The town is provided with electricity from the national grid, the main roads are tarred, but most roads in Kehemu are sandy and this makes them impassable for taxis in some areas. There is one public district hospital in town and this serves as a district and regional referral hospital. It is located 2 kilometres from the clinic that serves the Kehemu community. The maternity ward at the hospital has a capacity of 32 beds and had a monthly uptake of 300 women in 2009. [11] The bed occupancy rate for the maternity ward was $94 \%$ per month. The maternity ward was recently upgraded to a 200-bed capacity maternity hospital.

\section{Methods}

The study followed qualitative research principles to gather and analyse data, in order to facilitate exploration of perceptions and to generate in-depth understanding. ${ }^{[12]}$ A case study was conducted targeting women residing in Kehemu settlement and who had given birth - either using a publichealth facility for childbirth services or outside the public facility with the assistance of TBAs. This served as criteria for purposive sampling.

We initially identified 20 participants from the maternity records of all mothers who had delivered at the hospital. These were the only ones who met the study criteria at the time of identifying participants who delivered in the hospital. A similar number of clients were listed in the ANC register of a public clinic. The names on the ANC list - found missing in the maternity registers for the expected period for delivery - were identified as non-users of the public-health facility for deliveries. However, it was not easy to contact the mothers, as both registers had only the details of the location in which the mothers lived and not the specific residential addresses. A further attempt was made to contact mothers through a local radio announcement, but only two women reported themselves. After that, we decided to recruit those who came to post-natal care (PNC) follow-ups. Participants who delivered at a public health facility were contacted through the details recorded in the delivery and maternity admission registers in the ward.

A total of 20 women were recruited from the PNC. They were briefed about the aim of the study, and agreements were made for focus-group discussions.

The non-users of the public facilities were recruited with the assistance of the local midwife at the facility and three known TBAs in the area. Thereafter, women were identified and the researcher approached the clients and requested their agreement to participate in the study. Ten women were recruited from the TBA list, and together this made up a total of 30 women who met the study criteria and also agreed to be interviewed. They were divided into three groups. Dates and times were agreed to with each group of participants.

A focus-group discussion was chosen as the data-collection technique because it allowed the researcher to probe for rich data and for respondents to describe their views in their own words. It was also a good method for the researcher to exercise member checking techniques in order to validate the information collected.

We conducted three focus-group discussions with the 21 women who turned up. The first session consisted of seven women who delivered their babies at a public-health facility and the second session was with six women who delivered with the assistance of TBAs. The third group comprised women who delivered at the hospitals and some with the TBAs. The researcher used open-ended guiding questions during the discussions in order to extract information from the respondents.

The focus-group discussions were conducted in the Women's Development Centre Hall in Kehemu settlement. The site was chosen as it had no connection to the health facilities, and thus enhanced confidentiality and reduced anxiety among participants about reprisals from public health-care providers. Participants were met 30 minutes before the actual focusgroup discussion commenced in order to explain the procedures for and the process of the discussion. The focus-group discussion lasted 60 to 90 minutes. The discussion was conducted in one of the dominant dialects of the local language. This was agreed to by the participants. The focus-group discussions were subsequently tape recorded, transcribed and translated into English for analysis. Two women research assistants were recruited to assist with note-taking and to handle the tape recorder, as well as to observe clues provided by the non-verbal language of the participants.

\subsection{Data analysis}

The process of data reduction was used to analyse data. ${ }^{[13]}$ The process was organised into four main steps. The first was immersion of data, where the researcher engaged in repeated reading and rereading of data transcripts and tapes to digest what was said by participants. The second step was the process of coding, where the researcher examined and 
organised information from the entire interview into meaningful phrases. The creation of categories formed a third step in the qualitative data analysis, and the last step was the identification of themes. This last step involved explanations and interpretation of issues derived from the coded and categorised information. Explanations and interpretations of the research data were supported by the reflective field notes which the researcher had made during data collection, and by reviewing non-verbal and verbal clues collected during the focus groups. All focus group discussions were conducted between 08 and 14 August 2011.

\subsection{Trustworthiness}

Quality was assured by adhering to the four criteria proposed by Lincoln and Cuba. ${ }^{[14]}$ These criteria are credibility, dependability, conformability and transferability.

Accordingly, this occurred by allowing prolonged engagement with participants during data collection. In addition, we verified the data collected through the strategies of member checking and the audit trail. Interaction observation notes and diary accounts, as well as reflective notes, were also used throughout the process.

\subsection{Ethical considerations}

Ethical clearance for the study was obtained from the University of the Western Cape and the Ministry of Health and Social Services in Namibia. Written permission to conduct the study was granted by the Rundu district coordinating committee in Kavango region. Participants were recruited voluntarily and consent forms were signed prior to participation in the study. The researcher used pseudonyms to identify participants. All data were kept in a locked cupboard. The voice records were deleted and transcripts were destroyed after compilation of the study report.

\section{Results}

\subsection{Socio-demographic characteristics of participants}

Participants were of different ages and educational backgrounds. However, all share the same cultural background. Half of the participants interviewed were aged 16 to 24 years. Table 1 illustrates the age, parity, educational and economic status of the participants.

The participants indicated that the main form of marriage in their settlement was by custom recognition. This means they were living as husband and wife according to the traditional marriage system. However, a few participants had been married in terms of some or other religion.

Nine participants had only one child at the time the study was conducted, and more than half the participants had two or more children.
Table 1. Socio-demographic characteristics of participants

\begin{tabular}{ll}
\hline Characteristics & Statistics \\
\hline Age in years & 6 \\
$16-20$ & 7 \\
$21-25$ & 3 \\
$26-30$ & 2 \\
$31-35$ & 3 \\
35 and Above & 21 \\
Total & 2 \\
Average Parity & \\
Highest Education Level & $9(42.8 \%)$ \\
Primary & $7(33.3 \%)$ \\
Secondary & $3(14.2 \%)$ \\
College/University & $2(9.5 \%)$ \\
No Education & \\
Employment Status & $17(80.9 \%)$ \\
Employed & $4(19.0 \%)$ \\
Unemployed &
\end{tabular}

3.2 Women's preference in relation to hospital delivery Women in Kehemu described their preferences for place of delivery as depending on the support that was available at the time labour started. Women who used the public-health facility for deliveries based their choices on the information and services they received from the ANC clinic during pregnancy.

What they appreciated most was the skills of the nurses, which were evident during their assessment. They were satisfied with activities at the ANC and were informed of the benefits of using a public-health facility for deliveries during ANC sessions. this was mentioned as follows:

You never know about the measurement of blood pressure before you go into labour. Your blood pressure is monitored in the hospital and you know that high blood pressure is killing mothers unnoticed if they did not use [the] health facility for delivery. [P 17]

In addition, they found information provided to them during ANC useful, and this therefore encouraged them to continue to use the public-health facilities for other maternal services like deliveries and PNC. One of the participants who used a public-health facility for delivery expressed herself as follows:

I decided to deliver in the hospital because there is no skilled attendant to assist me at home. I trust the doctors will help more at the hospital ... [which will not be possible] at home. There

ISSN 2377-7338 E-ISSN 2377-7346 
could be complications such as excessive bleeding which cannot be properly managed at home [P 15].

The women were also motivated to use public-health facilities for delivery because services were affordable. Affordability was described in terms of clinic costs and admission fees payable to the state on registration or during consultation. The women's views on affordability were based on their exposure to other payable services received from the same institutions, which were more expensive Women were not charged for ANC, PNC, childhood immunisations and other consultations related to pregnancy and PNC. This was indicated as follows:

Fees are okay, anyone can afford because when you start at the clinic it is only four [Namibian] dollars! [P 3]

It is easy to keep a clinic fee aside for the day you will deliver. Anyone can help you to afford four dollars. After the first visit the doctors and nurses help you with ... [all other services] required. We also do not pay for family planning [services] - it is good! [P 2]

\subsection{Hindrances to delivering in the hospital}

The women related the contributing factors for delivery outside the public-health facility as being the ill timing of labour and the poor advice of the persons who assisted women during ANC, and, at times, during labour. Some women were put off by hearing other mothers' bad experiences and decided not to deliver at the hospital. This is what was mentioned:

It is not good to give birth on the way ... The parents asked me to try to give birth at home because it was at night and there was no transport. When transport was available it was time for the baby to be born and I delivered in the taxi (shaking their heads). [P 20]

My wish is always to deliver at hospital. When I left home I did not have pain, but while on my way to the river the pains came. No other help [was available] and I had to deliver on the way. [P 12]

The women described how it is impossible to use an ambulance because women in Kehemu did not have hospital contact numbers for emergencies. The women therefore got to the maternity hospital by walking or by using public transport. They also said that taxis are unreliable and thus they deliver at home or on the way to the hospital.

Published by Sciedu Press
The following statements described the women's experiences of attempting to access maternity care services at the publichealth facility.

I never thought of using an ambulance. Taxi is good only if you made an arrangement with the owner to call him when you will need him; at night it is difficult to get a taxi. It is better to use an ambulance. My sister-in-law assisted me; she stopped a taxi and gave all the history at the reception. [P 6]

One of the participants said that "Every birth is a different birth" - to give a sense of the unpredictability of the birth process.

Because, even if I wished to deliver in the hospital I cannot tell how long the pains will take before the baby comes. Sometimes shorter, another time longer - each pregnancy has its time. [P 7]

\subsection{The experiences of women who delivered in the hos- pital}

The general view of women regarding services in publichealth facilities was that it was a good experience. During their deliveries women felt a sense of security because of the skills and abilities of the personnel who could respond to birth complications. However, there was a mismatch between the skills that women expected from health workers and the way they were treated in practice. The health-workers' skills to cope with emergencies gave them confidence and security.

In the hospital I felt secure. I saw other women who had problems to deliver and they brought them and their babies from theatre. That was good, because there is equipment and [there are] doctors who can help you when labour becomes difficult. [P 18]

Yet the women also described a feeling of hopelessness in relation to the quality of care they received when they went to the maternity hospital because there were fewer nurses on duty.

They expected to be treated well or to be given good nursing care, but did not get what they wanted as nurses spent little time with each of them. As a result, the women described some of the nurses' practices as reprehensible. They found the nurses to be obnoxious, and their practices to be at times unsafe. Women were sometimes even left by themselves to deliver without a midwife alongside them. 
I delivered without a nurse attending to me. I called, but was told it is not yet time, I felt the baby is coming and when the new-born was out, the nurse rushed to me. [P 8]

I was pushed into the labour room and was instructed not to push as the baby was not yet near, but I felt the baby's head was already out and I pulled myself up towards a sitting position and the baby came out. [P 20]

In the women's view, slapping and shouting at a mother while she is in labour was the most disrespectful act committed by nurses in the maternity ward.

The pain I experienced while in labour was between heaven and earth! You cannot tell if you are yourself. When the nurse shouts at you and slaps you is when you realise that you are on earth. [P 2]

It is true! Women are slapped by nurses in the ward. For me they did not, but I witnessed a mother who delivered in the toilet. She was told to go and shower but did not make it, and the baby dropped! The nurse ran to her and slapped her, because she was putting the nurses into trouble. [P 12]

Although not all nurses behave in this way, the women's general feeling was that nurses were too busy. The respondents claimed that the nurses seemed to be busy with other tasks when the expectant mothers called for help and only attended to them after the worst had happened. Young women expected nurses to be friendly and helpful especially if they did not have experience of the labour process. They also had expectations based on the awareness created during ANC visits.

When asked if they knew about the customer-care desk where complaints from clients about services can be voiced, the women said they knew about it but did not use the opportunity to report incidents. They feared other good nurses might be implicated in such abuse, and that services might still not improve.

There was also uncertainty about the process of childbirth. Many confused the initial signs of the onset of labour with other ailments like stomach cramps. This was especially in women who were in labour for the first time. These experiences are illustrated in the responses below:

When pains came I did not know it was labour pain - but I complained of stomach cramps. [P 12]
My boyfriend and I did not have parents at home to guide us [as to] what to do while I was pregnant. ... We were asking other women who have experienced childbirth before to give us information on how to recognise labour. [P 6]

The nurses in the maternity ward usually advised them to go back and wait until the signs of "true labour" occurred. The women describe the act of sending them back to wait for the right time as being risky both for their lives and for that of the unborn baby.

The problem is when you are turned back to and from the maternity ward by nurses because you are not ready for labour; the taxi fare will be too much, [and] most women will not afford that and may end up not going back in time. [P 4]

\subsection{Improvements needed in service delivery in public- health facilities}

Women who had deliveries in the public-health facilities had several suggestions for improvements. The attitudes of the nurses in the maternity hospital were repeatedly emphasised by women as being the stumbling block in accessing the current services. The women described the attitude of health workers as "rude", "careless" and "disrespectful". The women suggested that more nurses be deployed on duty for every shift on the maternity ward. Their suggestion was based on the administrative tasks (paper work) that took up the time of the few nurses on duty. The women believed that the attitude of nurses could improve if they were not overworked.

The women also suggested that pain relief be provided, especially when incisions and suturing procedures are required. Women doubted whether the basic training and practice code of conduct for nurses prevented them from providing pain relievers during painful procedures.

Maybe their training should be improved. Suturing was done on me without any pain killer. It was too painful and should be improved. You can feel how the pain is pinching when she sticks the needle, the pain goes as she is pulling the string with the needle - and you feel each jerk as she is tying the knot of the string between your legs! No, it is painful! [P 21]

The use and reuse of dirty and soiled linen was generally noted by women as a practice in the maternity ward. The women stated that the explanation given by nurses for the used linen was that there was not enough in stock. Based on 
this explanation, the women suggested that enough linen, sanitary pads, as well as water proof covers for the linen, should be stocked in the maternity ward. The women claimed that they brought some items with them to the maternity ward but sometimes they ran out of their own and needed to be supported by the hospital stock which was not forthcoming.

At times they turn over the used linen to cover your bed while it is dirty. It is not right to reuse dirty linen. No linen to give. When I delivered I was put on a bed with dirty linen having blood spots. [P 1]

It is not good for your visitors to see your blood spots after delivery when they come to see you. It is not right. [P 19]

The women believed that arrangements should be made around the maternity hospital for a waiting shelter or waiting rooms - to be used in case they arrived earlier than the exact time of labour. This could ensure that the mother can access the service of a professional midwife or doctor in time. They further suggested that the maternity unit building be expanded in order to accommodate mothers who arrived before their delivery time. According to them, this extra space could also be used to accommodate mothers who cannot be discharged immediately after the delivery.

I think the hospital beds are few because they ask you to go home on the same day after delivery. There is no place to sleep! It is better to rest for at least one day more before you are discharged. [P 23]

There was a suggestion by women who were non-users of public-health maternity facilities that TBAs be linked to the health system. Their suggestion to the Ministry of Health and Social Services was to continue training TBAs, who should be provided with emergency delivery supplies. Some of the supplies mentioned include sterile gloves, linen savers, masks, antiseptic solution, normal saline and umbilical cord strings. The women indicated that these were some of the items already supplied to TBAs who have links with the health facilities.

It will be best if they are trained by hospital nurses, in terms of hygiene, in order for them to prevent harm and infection to the baby. [P 20]

Even though this suggestion was made by all three groups of women, as noted above, the women who used health facilities for delivery did not consider the TBAs' practices to be safe.
There were no recommendations from the women for improvements regarding transport problems when attempting to get to the hospital at night.

\section{Discussion}

The results of this study present pertinent issues related to the accessibility and acceptability of service provision in public-health facilities for pregnant women. In addition, women were motivated to use public-health facilities based on the information they received from nurses at the ANC about the benefits of using such services. These women referred to this information as being useful, and it is likely that this appreciation motivated many of them to continue using the public services. They appreciated the quality of services they received at the ANC. This finding is supported by Rockers et al., ${ }^{[15]}$ who conducted a study in Tanzania and argued that women who had a high number of ANC visits are more likely to deliver their babies in a health facility. The authors listed a range of motivators that will support women, including effective communication by service providers on "risks of home delivery, increased comfort with the health system and providers". ${ }^{[15]}$ In addition to awareness, women are influenced by the skills of the health staff and the quality of the health facilities. This was echoed by Onar et al., ${ }^{[8]}$ who indicated that the users are motivated by the availability of competent doctors, midwives, and other services and facilities. The findings of this study concur with these points, because women considered the setting and infrastructure for the services and skills of the staff as being acceptable and safe. In addition, the results concur with Culhane-Pera et al., ${ }^{[16]}$ who found that women preferred to deliver at hospitals because it is safe for the mothers there. In some developed countries, women feel safer to deliver at home than in a health facility. In a study conducted in Australia, findings indicated that educated middle-class women chose homebirth to retain control over their birth experiences. Their choice of choosing the home as a setting for giving birth is influenced by factors such as beliefs, convenience, affordability, reputation of midwives and past experiences. ${ }^{[17]}$

In our study, it was also indicated that adequate care and a good relationship with care-givers during delivery motivated the regular users of public-health facilities to go to the maternity hospital. This was also found by Beake et al., ${ }^{[18]}$ who studied women's experiences and expectations relating to their PNC in a maternity hospital in southern England. Women's satisfaction rating for the care they receive is based on the interaction with their caregiver. In this study, the interaction during ANC between women and the medical personnel contributed to the high expectations they had of the competence they could anticipate in nurses during childbirth. 
This motivated the users of the public-health facility to continue using the services. The importance of meeting patients' expectations is highlighted by Hodnett, ${ }^{[19]}$ who suggests that health-care providers should consider including better-thanexpected experiences in the plans for their patients.

While Izugbara and Ukwayi ${ }^{[5]}$ found that in most other African countries women use the services of TBAs because they cannot afford the user fees payable in public health-care systems, this was not the case in Kehemu. The absence of user fees for maternal health services in Namibia ${ }^{[20]}$ meant that the women described the clinic fee as affordable for everyone. This affordability could be one of the factors that motivated women to continue using public-health facilities.

Accessibility in this study was described in terms of the distance to the maternity hospital. Shorter distances made it easier for women to walk to the facilities without paying transport fees. However, the advantage of the shorter distance was limited - especially at night.

There were several factors that prevented women from using the maternity services offered by the public facility. Negative experiences were an important factor. These included painful procedures, uncaring attitudes of health workers, and the failure by health-care providers to give the needed care and support. Such experiences could lead to difficult relationships between women and care providers. ${ }^{[5]}$

Kruger and Schoombee, ${ }^{[21]}$ in their study in a South African maternity hospital, found that negative practices are sanctioned, viewed as part of the system of patient care, and are accepted by the patients (mothers) and nurses as if they are normal. Our study found that the patients in the maternity ward saw themselves as being merely recipients of services, and did not receive care in time when they requested it. This compares well with the argument by Kruger and Schoombee ${ }^{[21]}$ that mothers in the maternity hospital become docile, passive bodies in terms of medical care. This could be related to the observation women made about the nurses' tasks while they were in the maternity ward. This experience could influence the mother's decision to use alternative services - especially if she did not have enough information on the benefits of facility delivery.

Failure to use the public-health facilities also resulted from women being put off by descriptions of the negative experiences of others. Women who were users of public-health facilities shared experiences of painful procedures at the maternity hospital with others during informal gatherings. The women in this study described the attitude of health-care providers as not being conducive to care, especially when users felt neglected during the second stage of labour when nurses were preoccupied with other duties. It is likely that the situation where women felt neglected by their care provider could be due to what is described by Izugbara and Ukwayi ${ }^{[5]}$ as the impact of the gap in social standing between the care providers and the women - who are from poor families and of low social status. Kruger and Shoombee, ${ }^{[21]}$ in their South African study, found that nurses expected the women to obey instructions because of their superior knowledge and, by contrast, women expected compassionate care and respect and guidance during labour. Therefore, according to Beake et al. ${ }^{[17]}$ and Izugbara and Ukwayi, ${ }^{[5]}$ there was a mismatch between what the women wanted from the health-care providers and how they were actually treated. This influenced women's decisions to not use the maternity services offered by public institutions.

Simkhada et al. ${ }^{[4]}$ noted that the use of maternity health services is influenced by the distance that women have to travel or walk to the health facilities, and they explained that longer distances would negatively affect utilisation of services and vice versa. It was noted in this study that the women in Kehemu did not have problems reaching the hospital due to the distance involved, as the relatively short distance to the maternity hospital was an advantage for them when accessing services in the public-health facility. Despite the shorter distance, however, it was a problem at night when women in labour could not find transport to get to the maternity hospital. This is because they could not afford a special taxi fee which was payable on top of the day rate. This concurs with Culhane-Pera et al. ${ }^{[16]}$ who indicated that transportation and cost were a barrier for women in terms of delivering in maternity hospitals.

Kaingu et al. ${ }^{[22]}$ noted that TBAs still play a role in assisting women in poor resourced settings and suggest that their role should be recognised in maternal health-care provision. They further argue that TBAs should be linked to the formal system and should be trained in basic life-saving skills to provide a better safe service for the women. This was also a recommendation by the participants of this study.

\section{Recommendations}

Based on the results, the following recommendations are made:

First, the staff complement in the maternity hospital was inadequate. It is therefore recommended that the staff complement be reviewed in order to address the issue of the staff shortage.

Second, nurses in the ANC clinics should be made aware of what is happening in the maternity ward in order for them to address the information deficits of their clients. Women 
need information about pregnancy and the complications of the childbirth process, as well as about the benefits of using public health for delivery.

Third, the attitude of health workers needs to be changed. The district management should consider training nurses on caring practices. Fourth, delivery services at Nkarapamwe clinic in Kehemu should be expanded from the current 8 hours to include a 24-hour call-in service for maternity cases, with a well-advertised emergency call number for an ambulance service. This would bring services closer to the community and enhance support to women who are unable to secure transport at night.

Last, the Ministry of Health and Social Services should strengthen the training of TBAs in strategic locations, and they should be provided with emergency delivery supplies. The supplies should include sterile gloves, linen savers, masks, antiseptic solution or normal saline, and umbilical cord strings.

\section{Conclusion}

The study explored the perceptions of women on obstetric care in public-health facilities in a peri-urban area of Kavango east, Namibia. The women described services as being generally good and also acceptable. They also indicated that services were affordable.

The reasons for habitual users not using services were mainly circumstantial. There was no link between what was provided at the ANC and the service women receive in the maternity ward of the hospital. The nurses' attitudes at the ANC clinic might be more acceptable compared to those of the nurses in the maternity ward who were over-worked.

Women strongly expressed that transportation was a major hindrance for them in terms of reaching the hospital - especially at night-time. It can now be concluded that even though women who were users of public health facilities recognised the expert knowledge and experience of their care providers, the caring relationship was missing from providers at the maternity hospital in this study. The literature presented similar data to the views of the women in this study. Interventions such as pain relief for painful procedures, caring attitudes, and adequate supplies of linen and other necessities are measures that will make hospitals more acceptable as places for childbirth.

\section{CONFliCts OF INTEREST Disclosure}

The authors declare no conflicts of interest.

\section{REFERENCES}

[1] World Health Organization (WHO). 2017. Maternal mortality. Available from: http://www.who.int/gho/maternal_health/mo rtality/maternal_mortality_text/en/

[2] Ministry of Health and Social Services. Namibia Demographic and Health Survey 2006-2007. 2008. Available from: http://dhspro gram.com/pubs/pdf/FR204/FR204c.pdf

[3] Ministry of Health and Social Services. Namibia Demographic and Health Survey 2013. Available from: http: //dhsprogram.com/p ubs/pdf/FR298/FR298.pdf

[4] Simkhada B, Teijlingen E, Porter M, et al. Factors affecting the utilization of antenatal care in developing countries: Systematic review of the literature. Journal of Advanced Nursing. 2008; 61(3): 244-260. https://doi.org/10.1111/j.1365-2648.2007.04532.x

[5] Izugbara C, Ukwayi J. An intercept study of persons attending traditional birth homes in rural south-eastern Nigeria. Culture, Health \& Sexuality. 2004; 6(2): 101-114. https://doi.org/10.1080/13 6910501198851

[6] Turan J, Miller S, Bukusi E, et al. HIV/AIDS and maternity care in Kenya: How fears of stigma and discrimination affect uptake and provision of labor and delivery services. AIDS Care. 2008; 20(8): 938-945. https://doi.org/10.1080/09540120701767224

[7] Maimbolwa M, Yamba B, Diwan V, et al. Cultural childbirth practices and beliefs in Zambia. Journal of Advanced Nursing. 2003; 43(3): 263-274. http://doi.org/10.1046/j.13652648. 2003. 02709. $\mathrm{x}$

[8] Onah H, Ikeako L, Iloabachie G. Factors associated with the use of maternity services in Enugu, South-eastern Nigeria. Social Science
\& Medicine. 2006; 63(7). http://doi.org/10.1016/j.socsci med.2006.0.019

[9] Abdullah A, Hort K, Butu Y, et al. Risk factors associated with neonatal deaths: A case-control study in Indonesia. Global Health Action. 2016; 9: 30445. https://doi.org/10.3402/gha.v9.30445

[10] MIS (Management Information System). Annual maternity summary. Kavango Health Regional Directorate. 2010.

[11] Ministry of Health and Social Services (MoHSS). Annual report Kavango RMT, 2009.

[12] Creswell JW. Educational research: Planning, conducting and evaluating quantitative and qualitative research. Harlow: Pearson Education; 2014.

[13] Green J, Willis K, Hughes E, et al. Generating best evidence from qualitative research: The role of data analysis. Australian and New Zealand Journal of Public Health. 2007; 31(6): 545-50. https://doi.org/10.1111/j.1753-6405.2007.00141.x

[14] Polit DF, Beck CT. Nursing research: Generating and assessing evidence for nursing practice. Philadelphia: Wolters Kluwer; 2008.

[15] Rockers PC, Wilson ML, Mbaruku G, et al. Source of antenatal care influences facility delivery in rural Tanzania: A populationbased study. Maternal Child Health Journal. 2009; 13: 879-885. https://doi .org/10.1007/s10995-008-0412-7

[16] Culhane-Pera KA, Sriphetcharawut S, Thawsirichuchai R, et al Afraid of delivering at the hospital or afraid of delivering at home: A qualitative study of Thai Hmong families' decision-making about maternity services. Matern Child Health Journal. 2015; 19: 2384-2392. https://doi.org/10.1007/s10995-015-1757-3 
[17] Dahlen HG, Barclay LM, Homer C. Preparing for the First Birth: Mothers' Experiences at Home and in Hospital in Australia. Journal of Perinatal Education. 2008; 17(4): 21-32. https ://doi .org/10 $.1624 / 105812408 \times 364143$

[18] Beake S, Rose V, Bick D, et al. A qualitative study of the experiences and expectations of women receiving in-patient postnatal care in one English maternity unit. BMC Pregnancy \& Childbirth. 2010; 10: 1070-78. https://doi.org/10.1186/1471-2393-10-70

[19] Hodnet ED. Pain and women satisfaction with the experience of childbirth: A systematic review. American Journal of Obstetrics and Gynecology. 2002; 186: 160-172.
[20] Ministry of Health and Social Services (MoHSS). National Outreach Guidelines for Health Care Services. Windhoek: MoHSS; 2010.

[21] Kruger L, Schoombee C. The other side of caring: Abuse in a South African maternity ward. Journal of Reproductive \& Infant Psychology. 2010; 28(1): 84-101. https://doi.org/10.1080/026468 30903294979

[22] Kaingu C, Oduma J, Kanui TI. Practices of traditional birth attendants in Machakos District, Kenya. Journal of Ethnopharmacology. 2011; 137(1): 495-502. https://doi.org/10.1016/j.jep.20 11.05 .044 